\title{
Inmigración venezolana y estigmatización laboral en el Perú
}

Recibido: 25/03/2020

Aprobado: 04/05/2020

Jerjes Loayza

Publicado: 25/08/2020

Universidad Nacional Mayor de San Marcos

<mloayzaj@unmsm.edu.pe>

\begin{abstract}
RESUMEN
La migración venezolana, al día de hoy, es el suceso migratorio más impactante en el devenir de la historia peruana debido a su elevado número. Se estudian las intersubjetividades durante los ańos 2017 a 2019, con especial énfasis en el estudio del cuerpo y de las emociones migrantes insertas en el intercambio de valoraciones subjetivas. Para ello se aplican entrevistas a profundidad, historias y memorias de vida a mujeres y hombres migrantes de nacionalidad venezolana en las ciudades de Lima, Ayacucho, Chiclayo y Cusco. Se reconocen rencores, enfrentamientos y prejuicios entre peruanos y venezolanos, los cuales son potenciados por los medios de comunicación. El choque de costumbres, pensamientos y creencias incluirían brotes de xenofobia y patriarcalismo que, si bien provocaría la radicalización de la desigualdad, se debe entender en la dinámica ya conocida de la discriminación y violencia contra la mujer que venía desarrollándose en Perú de manera estructural. Finalmente se destaca la constancia del migrante venezolano para reinventar nuevas dinámicas que buscan a la aceptación peruana para su inserción laboral en el país.
\end{abstract}

Palabras Clave: Migración venezolana, desigualdad, xenofobia, informalidad, capital social.

\section{Venezuelan inmigration and labor stigmatization in Peru}

\begin{abstract}
Venezuelan migration, to this day, is the most impressive migratory event in the future of Peruvian history due to its high number. Intersubjectivities are studied during the years 2017 to 2019, with special emphasis on the study of the body and migrant emotions inserted in the exchange of subjective evaluations. For this, in-depth interviews, stories and memories of life are applied to migrant women and men of Venezuelan nationality in the cities of Lima, Ayacucho, Chiclayo and Cusco. Grudges, confrontations and prejudices between Peruvians and Venezuelans are recognized, which are promoted by the media. The clash of customs, thoughts and beliefs would include outbreaks of xenophobia and patriarchalism that, although it would cause the radicalization of inequality, must be understood in the already known dynamics of discrimination and violence against women that had been developing in Peru in a structural way. Finally, the perseverance of the Venezuelan migrant to reinvent new dynamics that seek Peruvian acceptance for their labor insertion in the country stands out.
\end{abstract}

KeYwords: Venezuelan migration, inequality, xenophobia, informality, social capital.

1 Investigación realizada como parte del proyecto con financiamiento "Discriminación, movilidad social y desigualdades socio culturales en la migración venezolana en el Perú desde el año 2017 a 2019”, con código E19151941, avalado durante el año 2019 por el Vicerrectorado de Investigación y Posgrado de la Universidad Nacional Mayor de San Marcos. Dicho proyecto se encuentra en el marco del grupo de investigación "Estado, Nación y Democracia en el Perú y América Latina”. 


\section{Introducción}

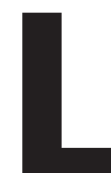
a historia de las migraciones internacionales en la República del Perú ha sido muy diversa debido a su vínculo causal en la discriminación sustentada por el racismo científico enarbolado durante el siglo XIX e inicios del siglo XX. Inusitadamente, durante el ańo 2017 se produjo un intenso proceso migratorio ${ }^{2}$ que propició una serie de problemas: explotación laboral, procesos xenofóbicos y trata de personas. Los inmigrantes venezolanos, en su intento por conseguir trabajo, se han insertando en la vorágine informal que caracteriza las magras estructuras laborales del Perú. Económicamente su inserción ha provocado un subempleo aun mayor, generando desconfianzas y miedos, muchas veces producto de los temores infundados. Aunque en un inicio el gobierno desarrollaba esfuerzos por insertar, de la mejor manera a las grandes cantidades de migrantes venezolanas dado que no podía desconocer importantes tratados internacionales ${ }^{3}$ firmados en donde acataba la migración como un derecho fundamental, ha tenido que enfrentar un amplio desacuerdo de numerosos sectores peruanos que rechazan la migración venezolana debido a la pornografía de la violencia que los medios de comunicación propiciaron en diferentes momentos en que el delito lo protagonizó el migrante venezolano. Como producto de dicha presión, en agosto del año 2018 se volvió obligatorio el pasaporte para todo venezolano que deseaba ingresar al Perú, siendo una medida disuasiva dado el alto costo de dicho documento en Venezuela. ${ }^{4}$ Sin embargo existirán Organizaciones no Gubernamentales que intentarán convertirse en

2 Según la Oficina General de Planeamiento y Presupuesto 248038 ciudadanos venezolanos ingresaron al Perú y se acogieron al trámite de Permiso Temporal de Permanencia - PTP, por los DS N ${ }^{\circ} 002-$ 2017-IN, DS N ${ }^{\circ} 023-2017-I N$, DS N ${ }^{\circ} 001-2018-I N$ y DS No $007-$ 2018-IN, desde el 02 de febrero del 2017 hasta el 30 de setiembre del 2018. (p.7)

3 Convenios de la Organización Internacional del Trabajo (OIT) relativos a "Los trabajadores migrantes" (Convenio 97) y a "Las migraciones en condiciones abusivas y la promoción de la igualdad de oportunidades y de trato de los trabajadores migrantes" (Convenio 143); así como la Declaración sobre los derechos humanos de los individuos que no son nacionales del país en que viven (1985) y la Convención Internacional para la protección de los derechos de todos los trabajadores migratorios y sus familiares (CTM). (p. 69) Recuperado de https://www.defensoria.gob.pe/wp-content/ uploads/2018/05/informe-146.pdf

4 Recuperado de https://theconversation.com/asi-es-como-peru-cerro-sus-puertas-a-los-migrantes-venezolanos-127975 actores con la suficiente capacidad de presión sobre el Estado para difundir el enfoque de derechos humanos sobre los migrantes (Bobes, 2017). Inclusive el gobierno se ha visto obligado a facilitar la entrega de bonos de ayuda económica y canastas de alimentos con ayuda de organismos internacionales como ACNUR y la Unión Europea a los sectores venezolanos más vulnerables, afectados por la cuarentena a partir del mes de marzo del $2020 .^{5}$

Social y culturalmente se desarrollarían, según se sostiene, una serie de aspectos que justifican la presente investigación: una inusitada xenofobia contra la población venezolana que se experimenta en una mala relación entre migrantes en busca de trabajo y una población decidida a criticar la llegada incesante de miles de venezolanos. Ello ha representado, a su vez, una actitud patriarcal contra la mujer venezolana la cual ha sido tildada de numerosas formas negativas debido a su comportamiento diferenciado con la mujer peruana. Los miedos, temores y necesidades que marcan la vida de miles de venezolanos en el Perú conllevan a un estudio capaz de profundizar en un fenómeno reciente que, a su vez, viene generando una preocupación creciente en la población peruana debido a su impacto económico y cultural. Asimismo, el estudio es pertinente porque permitirá entender otros procesos de larga data en el Perú, el del racismo y el del patriarcalismo, ambos insertos tanto en la cotidianidad como en las instituciones y organizaciones del país. Sostenemos que la inmigración venezolana permitiría construir, gracias al contraste con el imaginario nacional, una mirada sociológica más profunda de dichos procesos a partir de la experiencia del migrante venezolano. Es, entonces, gravitante entender el impacto del proceso migratorio más relevante en la historia de nuestra república, tanto por su número como por su impacto en lo económico, lo político y lo socio cultural.

Siendo así, la investigación que se presenta se pregunta las consecuencias de la interacción intersubjetiva del inmigrante venezolano en pobladores peruanos en su constante interacción en las calles de Lima, Cusco, Ayacucho y Chiclayo desde el año 2017 a 2019. Como objetivos específicos se busca explorar el imaginario social construido por el migrante

5 Recuperado de https://gestion.pe/peru/covid-19-venezuela-mre-lacomunidad-de-migrantes-venezolanos-en-peru-recibira-apoyo-economico-adelanto-el-mre-noticia/ 
venezolano en torno a los aspectos negativos y positivos de trabajar y vivir en Perú. Asimismo se plantea estudiar las amenazas insertas en el mundo cotidiano del migrante venezolano, con especial énfasis en la explotación de la que es objeto no solo de manera laboral, sino a partir de exigencias o requerimientos comunes dada su condición migrante. Finalmente se busca comprender las estrategias de la población venezolana para afrontar las dificultades de su rechazo en el entorno peruano. La investigación presentará los detalles de la metodología cualitativa seleccionada, una breve revisión teórica en torno al tema de las migraciones y los resultados debidamente divididos de acuerdo a los objetivos específicos planteados.

\section{Metodología}

La investigación se desarrolla desde una perspectiva no experimental, transversal y a partir de un entrada comprensiva. Para ello se desarrollará un trabajo de campo especialmente diseñado en cuatro regiones del país: Lima, Ayacucho, Cusco y Chiclayo. La selección de dichas ciudades obedece a una muestra por cuotas. Lima, representa la capital del país con mayor cantidad de migrantes venezolanos. Ayacucho representa una región del área andina que, a diferencia de Cusco, posee vínculos y comportamientos colectivos tradicionales de la mano con una ciudad de $180 \mathrm{mil}$ habitantes. El caso de Cusco es distinto, se trata de una ciudad globalizada con presencia de turistas provenientes de todo el planeta. Además a ello se le suma una población de 428 mil habitantes. El caso de Chiclayo, con más de 552 mil habitantes, pasa por ser no solo la tercera ciudad más poblada de la costa después de Lima y Trujillo, sino una ciudad que nos permitiría conocer el fenómeno migratorio en la costa, sin detenernos únicamente en Lima.

La muestra fue estratificada, para generar una máxima cantidad de casos que atiendan cuotas de perfiles laborales, tanto calificados como no calificados. Para ello se recurrió a individuos que colaboraron con la investigación generando, a la vez, una muestra voluntaria. Cabe destacar que se prefirieron migrantes pertenecientes a un trabajo informal, así como aquellos sumidos en una situación de necesidad extrema, tales como mujeres pidiendo dinero en la calle junto a sus menores hijos. La investigación se desarrolló durante el ańo 2019, accediendo a un trabajo de campo dividido en dos métodos: el etnográfico y el biográfico.

En cuanto al método etnográfico, se aplicó la técnica de la observación participante, asistiendo a calles, jirones, mercados, transporte público, espacios públicos en general, identificando una serie de comportamientos estigmatizantes, así como actitudes amicales, de negociación intersubjetiva y, en general, todo tipo de micro vínculos entre mujeres y hombres de ambas nacionalidades. La observación se desarrolló diariamente en la ciudad de Lima, aprovechando la inserción del investigador en diferentes espacios de masiva migración venezolana, tales como el distrito de San Juan de Lurigancho. En el caso de Chiclayo, se visitó las avenidas principales en que había una gran cantidad de migrantes ofreciendo productos y servicios de belleza en la vía pública. En el caso de Ayacucho se observaron a migrantes pidiendo dinero en las calles. En el caso de Cusco se visitaron restaurantes y calles para acceder no solo a los migrantes, sino los prejuicios de los peruanos instalados en Cusco.

En cuanto al método biográfico, se utilizaron tres técnicas distintas:

- Entrevista a profundidad: Duró aproximadamente 60 minutos, sumados a través de repetidos encuentros, variando entre 1 y 3 momentos de interrelación entre investigador y entrevistado. El espacio elegido fue elegido por el entrevistado, pudiendo ser un restaurant, un parque, un café o un centro comercial. Se obtuvo un total de 6 entrevistas.

- Historia de vida: Se aplicó a la par con la entrevista para provocar una serie de relatos que incursionen en la experiencia de vida antes y después del proceso migratorio. Se aplicó un total de 3 historias de vida.

- Memoria oral: Se buscó identificar los prejuicios, mitos e imaginarios intersubjetivos sostenidos en torno a la experiencia migrante venezolana. Se logró un total de 6 entrevistas de 15 minutos cada una.

Cabe destacar que también se aplicaron entrevistas etnográficas, las cuales si bien no poseen un esquema predeterminado de preguntas, propician diálogos al amparo de algún servicio o intercambio contingen- 
te entre el entrevistador y algún migrante venezolano o venezolana. En total se tuvo 11 entrevistas: 4 en Chiclayo, 4 en Cusco, 1 en Lima, 2 en Ayacucho, así como un testimonio etnográfico en Lima.

\section{Marco teórico}

Tal como plantean Dunning y Elías (1992) es importante entender los procesos identitarios insertos en las dinámicas cotidianas dado que representan la "otra cara de la moneda del control y de las restricciones que coartan nuestra expresión emocional en la vida corriente: no es posible entender la una sin la otra" (Dunning y Elías, 1992: 87). Se parte, por ello, del concepto de identidad dado que, inclusive, la propia necesidad de razonar termina siendo penetrada por todas las etapas de los pensamientos y las decisiones basadas en la identidad (Sen, 2000). Las identidades son, a su vez, penetradas por fenómenos de globalización como producto del intenso intercambio económico, político y cultural: se forja una obligación a comportarse socialmente de acuerdo a las normas o "valores" del nuevo nacionalismo globalizado, concebido como "el Occidente global" (Varese, 2011: 292). Tal como sugiere la literatura sistematizada en temáticas de migración:

La migración no puede ser entendida considerando únicamente lo económico, que representa tan sólo una de sus dimensiones; es necesario (...) intentar acercarse a los complejos y sutiles anudamientos entre sus aspectos funcionales, simbólicos e imaginarios; tratar de penetrar en las cadenas de significación que hacen de la migración una institución en el sentido pleno de la palabra. (Albarrán y Manero, 2010: 171)

Para entender la lógica de la migración, se partirá de la noción del migrante como "aquel actor social que ha logrado ejercer un control regularizador sobre sus actividades viviendo su historicidad y se ha desprendido de normas y formas de reproducción para producir su propio modelo cultural" (García y Armas, 2011: 118). El caso peruano se caracteriza en su historia por haber protagonizado una ciclo repetitivo de crisis económica, inmerso en el acostumbrado racismo criollo, "heredero de las estructuras coloniales sobrevivientes, impidiendo la integración en el nue- vo escenario" (Escárzaga, Abanto y Chamorro, 2002: 279). Dado este escenario, el caso de la migración venezolana en el Perú, podría dar lugar a situaciones de soledades entre los grupos en donde habrá establecidos (limeńos) frente a marginados (venezolanos) bajo una lógica en donde "o bien la mayoría de los ciudadanos son ignorantes e indiferentes a la vida interna de los otros grupos, o bien las relaciones entre diferentes grupos están empañadas por sentimientos de resentimiento y molestia" Kimlycka (2003:56).

En efecto, la restricción el enfrentamiento y conflicto de intereses entre los recién llegados y los establecidos provoca situaciones límite en donde "por una parte, se configuran en sujetos formales de derechos y atención institucional prioritaria dada su vulnerabilidad y, por la otra, se convierten en vecinos sospechosos, estigmatizados y rechazados" (Osorio, 2014: 39-40). Más aún se identificarán escenarios en donde los gobiernos de los países receptores desarrollarán "un discurso discriminatorio y criminalizador que concibe a los inmigrantes como una carga para la sociedad receptora y como un peligro para la seguridad interna" (Delgado, 2016: 170). Si a ello se le añade lo que Guerra (2012: 207) plantea como "políticas migratorias regidas por la renacionalización y criminalización (que fomentan) la clandestinidad, provocando cuadros de explotación laboral y sexual", dificultará el tratamiento de dicha problemática. En estos casos los estados desarrollarán una administración discrecional amparada en cierta arbitrariedad, concibiendo una lógica de la discriminación, acrecentando la vulnerabilidad y la inseguridad (Guerra, 2012).

Se generará, de esta manera, una enorme imposibilidad de enfrentar la presión del país de recepción que se manifiesta, según establece Delgado (2016), en la creciente criminalización de los migrantes, el desprecio de la fuerza de trabajo y el sometimiento a condiciones provocadoras de vulnerabilidad, exclusión social y explotación extrema. La tendencia, por ello, se manifestará en "la subvaloración de los diplomas de los migrantes, los bajos salarios, y el desconocimiento de sus derechos sociales" (Castro, 2010: 75). Ello es contradictorio en la medida que "el trabajo es considerado dentro de un sistema de derechos y deberes regidos por su utilidad colectiva, y no ya solamente por la utilidad económica de los intercambios mercantiles. Es a partir de esas carac- 
terísticas sociales, públicas, colectivas, que puede comprenderse que el trabajo se convierta en el fundamento de una ciudadanía social" (Castel, 1998: 68). Ahora bien, entre las posibles consecuencias del fenómeno migratorio, se aprecia la crónica circunstancia de una movilidad social cuyo vaivén se convertiría en una amenaza constante para el migrante, marcada por la contingencia e incertidumbre:

Una persona migrante podría experimentar movilidad social "hacia arriba" en relación con su lugar de origen: gana su dinero, dispone de ello, le da seguridad, provee a sus hijos/as; pero también movilidad social "hacia abajo" respecto del país de destino: casos de personas cualificadas desarrollando trabajos poco cualificados y sin tener mayores opciones de cambiar esta situación. (Retamozo, 2014: 59)

De la mano con la bibliografía mencionada, se buscará plantear en el presente estudio un enfoque en donde los migrantes no aparezcan como meros sujetos pasivos, sino como "sujetos activos y promotores de sus dinámicas de poder y como parte de un proceso de reconstitución política" (Coraza De los Santos, 2014: 207). Ello se suma a la necesidad de "identificar, redefinir y repartir responsabilidades en los ámbitos local, regional y global, así como formular nuevas e imperativas representaciones legales de la solidaridad humana" (Dos Santos, 2012: 434-435). Sostenemos, al igual que Rocha (2017), la necesidad de rebasar la definición clásica de ciudadanía civil, política y social, dado que es incapaz de responder los dilemas propios de la migración.

\section{Contexto socioeconómico de la migración venezolana}

Las consecuencias de la migración venezolana en el Perú radicarían en diferentes frentes. Así, económicamente, su inserción ha provocado un subempleo que raya en la explotación de mano de obra venezolana6, puesto que, confundida con la promoción del acoso sexual en las mujeres y hombres venezolanos. En este

6 Para el ańo 2019 un 46\% de los trabajadores venezolanos ganaba menos del salario mínimo vital reconocido en Perú. Recuperado de https://gestion.pe/economia/management-empleo/cuales-son-losabusos-laborales-que-sufren-los-migrantes-venezolanos-noticia/ aspecto el sector femenino soportaría numerosos ataques sexuales callejeros y laborales sostenidos en el Perú. En este sentido, el estudio de Vallejo y Rivarola (2013) nos ayuda a entender dicha estructura contra la mujer en el Perú, dado que se normalizan, invisibilizan y legitiman las experiencias de acoso sexual callejero hacia las mujeres. Políticamente la población peruana ha desarrollado una pertenencia cada vez más sostenida del prejuicio a todo migrante venezolano, confundiéndose muchas veces con un proceso de xenofobia que los ha llevado a múltiples escenas de violencia. Un ejemplo de ello es el caso de un peruano y un venezolano que protagonizaron una pelea en el transporte público durante el ańo 2018:

Peruano: "vienen a nuestro país como ratas. En lugar de luchar, salen corriendo como ratas, parecen ratas. Deben quedarse, luchen por su país, liberen a su país. Huyen como cobardes".

Reportera: "al ver que el vendedor venezolano se estaba alterando, el cobrador del bus le pidió que se bajara, y aparentemente este accedió de inmediato. Sin embargo, segundos después, apareció por la puerta trasera del carro y golpeó en la cabeza al sujeto que lo estaba insultando. La gresca se desató y ambos se dieron de puñetes y patadas"7.

Social y culturalmente se desarrollarían dos de los principales aspectos más contradictorios a nivel emocional e intersubjetivo: el racismo y el patriarcalismo amparado en la exclusión de género, lo cual se encuentra inserto en la costumbre de la población nacional, de acuerdo a las particularidades locales. Con la llegada de la migración venezolana cada uno de estos aspectos se magnifica debido a los contrastes estéticos, sexuales y educativos que todo peruano identificará en los migrantes venezolanos. Así, las desconfianzas se confundirán con procesos xenófobos que antes de discriminar al migrante buscarían comprender la pertenencia de clase de alguien que no guarda relación con el tipo de movilidad social que implica vivir en el Perú: si se es blanco, educado y hombre ya habrá un juicio prediseñado; si se es mujer con ropas ceñidas y con cuidado de la apariencia estética habrá otro prejuicio patriarcal prediseñado que llevará a un duro contraste entre lo que se viviría en Venezuela de lo que se vive en Perú.

7 Recuperado de https://www.youtube.com/watch?v=G6dOrTukF1o 
Por su parte, los migrantes venezolanos estarían construyendo un imaginario negativo lo suficientemente camaleónico para soportar y superar la presión y el estrés producto de la explotación laboral y del posible acoso del cual serían objeto, en especial las poblaciones migrantes no calificados o sin posibilidad de desarrollar la profesión estudiada. Para ilustrar dicha presión sobre los migrantes venezolanos, García y Restrepo (2019) identifican diversas consecuencias en lo que va del último año, tales como el "desplazamiento de personas y familias de un contexto cultural a otro, concentrando una cadena de narraciones que registran la transformación de las redes sociales, culturales e identitarias, las necesidades económicas, la xenofobia, el racismo y la construcción de un espacio liminal que ocupan los venezolanos llegados en la sociedad de recepción" (Garcíay Restrepo, 2018: 16-17).

En este contexto, según estudian los autores, la realidad que enfrenta la migración venezolana implica tanto el proceso de establecimiento en la sociedad de destino, así como "la relación en sociedades donde el rechazo al extraño llega inclusive a desatar maneras violentas" (García y Restrepo, 2018: 13). Podemos citar un testimonio que refleja la importancia del esfuerzo denodado que vienen realizando: "tendré un capital suficiente para poder trabajar en un negocio en Venezuela" 8. Todo esfuerzo, pareciese decirse, tiene su recompensa. Lo importante de esta posición sacrificada será negociar, día a día, un lugar intermedio en que puedan tolerar $y$, hasta cierto punto, comprender los prejuicios y dificultades que vivirían en Perú, no solo relacionados a lo que sufren por ser migrantes, sino a las estrategias utilizadas por los empleadores para engańar, timar o imponer determinada carga laboral en el mundo de la informalidad.

\section{Explotación laboral de la mano de obra inmigrante}

La Oficina del Alto Comisionado para los Derechos Humanos (ACNUDH) informa que, al año 2020, todo migrante en situación irregular vive y trabaja clandestinamente con temor a emitir queja alguna, lo que promueve una mayor discriminación, explo-

8 Entrevista aplicada en Puerto Eten, Chiclayo en setiembre de 2019. Hombre de 23 ańos de Mérida. Vive con toda su familia en Perú. Trabaja como mesero en un restaurante de Puerto Etén. tación y marginación, a diferencia del resto de la población? . Por otra parte, la investigación de Borland, Buller, Vaca, Stoklosa y Zimmerman (2015), desarrollada mediante entrevistas a migrantes bolivianos en Argentina, demuestra los niveles de explotación en empresas textiles, en donde estaban obligados, mediante un mero acuerdo verbal, a trabajar hasta 12 horas diarias, con una mala paga y la exposición a posibles accidentes laborales. Un testimonio, referido a este punto, es el de un migrante ${ }^{10}$ en Chiclayo que comenta la profunda explotación que ha sufrido nos permite ver la ambivalencia de la razón de vivir en Perú:

La mejor experiencia que he tenido es el trabajo. La peor experiencia que he tenido es la explotación laboral. Creo que la situación de explotación en Lima está más agudizada que en provincias.

¿Qué haces en tus ratos libres?

Todo el tiempo que tengo lo ocupo en el trabajo porque siento que de esa forma no extraño a mi familia.

El trabajo es lo mejor que tiene el Perú, pero, a la vez, el trabajo termina siendo la peor experiencia vivida debido a la recurrente explotación. Incluso los momentos libres se limitan al trabajo, y no solo como la búsqueda de una acumulación ilimitada, sino para evitar que la nostalgia circunscriba al migrante en una profunda depresión. Otra entrevistada ${ }^{11}$ en Chiclayo piensa el trabajo y el dinero como la principal vía para vivir, ser feliz o, en el peor caso, vivir desgraciadamente:

¿Cuánto tiempo piensas quedarte en el Perú?

El tiempo que me tome estabilizarme económicamente para mandar dinero a mi familia en Venezuela (...) La mejor experiencia que he tenido es poder encontrar un trabajo para seguir luchando con mis hijos (...) La peor experiencia que he tenido es no tener un lugar donde dormir y pasar hambre por varios días.

9 Disponible en https://www.ohchr.org/SP/Issues/Migration/Pages/ MigrationAndHumanRightsIndex.aspx

10 Entrevista aplicada en Zaña, Chiclayo, Hombre de 32 ańos. Trabaja montando canchas de gras artificial. Vive en Chiclayo desde noviembre del 2019.

11 Entrevista aplicada en la ciudad de Chiclayo en setiembre de 2019. Mujer de 26 años natural de Aragua. Tenía 2 semanas de haber llegado a Chiclayo. Vive con uno de sus hijos de 8 ańos y el otro menor aún vive en Venezuela. 
En un testimonio desarrollado en la ciudad de Cusco, un migrante venezolano ${ }^{12}$ comenta la necesidad de haber migrado con su familia entera debido a la urgencia de requerir algún trabajo. Sin embargo el engaño del que fue víctima en Lima le obligó a dedicarse a la venta ambulatoria de caramelos:

Trabajaba en construcción. Llegamos a Lima y empezamos a trabajar en construcción pero nos estafaron, estuvimos trabajando como cinco meses pero no nos pagaron.

\section{¿Fuiste a exigir, a pedirle, fuiste con la policía?}

Estuvimos reclamando fuimos al ministerio de trabajo y la compañía no existía.

\section{Cuéntame un poco ¿cómo pasó eso?}

Yo he trabajo con cuatro señores, el último que me chocó más fuerte es el que no me pagó los cinco meses. El 24 de diciembre estaba esperando un billete para comprarme mis cosas y traérmela a ella, y sabe lo que me dice el tipo el veinte cuatro de diciembre, que no había presupuesto. Le dije al señor págame a mí, y me conseguí otro compatriota y lo fuimos a buscar, lo esperamos en el centro y lo rodeamos, que no tengo billete para hoy, que yo quiero mi billete para hoy porque no tengo ni un centavo encima, yo he trabajado como un burro aquí y quiero mi billete.

La explotación laboral reflejaría el abuso a manos de algún empleador que, con el fin de maximizar las ganancias de su propio negocio, utilizaría el desempeño venezolano para incrementar las ventas y disminuir el posible salario que representaría la paga del exceso de horas permitidas legalmente. A ello se le ańade el acoso callejero y el acoso sexual en espacios laborales y en el espacio público. Por ejemplo, se identificaron diversos casos entre enero y setiembre del año 2019: hasta 213 mujeres venezolanas inmigrantes fueron rescatadas de la trata de personas de la que fueron víctimas, incluyendo menores de edad. El caso de una de ellas, que fue captada como posible maestra auxiliar, termino en manos de un hombre que la obligó a prostituirse13. Las mujeres venezolanas serían objeto de crítica sostenida dada su presencia de mujer sin la

12 Entrevista aplicada en Cusco en octubre del 2019. Hombre de 24 años. Llegó a Perú de la ciudad de Margarita en octubre del 2018. Es casado y tiene un nińo de 4 años. Toda la familia vive en Perú. Trabaja vendiendo chutepes en Cusco

13 Recuperado de https://larepublica.pe/sociedad/2019/12/08/venezuela-crece-el-numero-de-extranjeras-victimas-de-trata-venezolanasexplotacion-sexual/ moral y decencia de la mujer peruana, según implica la construcción del género en un país conservador y patriarcal como el Perú.

De esta manera se comprueba que el factor género incrementa la vulnerabilidad migratoria, propiciando escenarios de "violencia sexual y captación para redes de trata para la explotación laboral y sexual, pero también, en la inserción como trabajadoras en sectores laborales especialmente precarios y susceptibles de abusos, sobreexplotación e incluso esclavitud". (Guerra, 2017: 200). Inclusive se avizoran familias internacionales que experimentan un vínculo familiar en la lejanía transnacional generando "cambios en términos de la estructura del hogar en el lugar de origen y destino, así como desafíos para el cuidado de los miembros dependientes" (Maldonado, 2018: 3).

\section{Patriarcalismo y xenofobia contra la inmigración venezolana}

Su condición femenina caracterizada por atuendos ceñidos, maquillaje diverso y, en términos generales, un trato más horizontal con clientes o personas en general, derivará en duros adjetivos que intentarán menospreciarlas originando diferentes episodios de violencia pública en su contra ${ }^{14}$. Un ejemplo de ello proviene de un migrante ${ }^{15}$ con apenas 11 días en Perú quien indica los insultos a él y a su pareja que ha tenido que soportar en tan poco tiempo: "La peor experiencia que he tenido es recibir insultos cuando pido ayuda o trabajo en la calle, como ladrón o vago, y esto me incomoda mucho porque estoy en el Perú por necesidad. También insultaban a mi pareja, le dicen roba maridos, prostituta, etc." Se asiste a la "aparición de un estigma y el sufrimiento de la deslegitimación de la persona y la violación de su dignidad" (Peláez, 2016: 227).

14 El Ministerio de la mujer y poblaciones vulnerables (2016) expone estadísticas que reflejan las prácticas perniciosas contra las mujeres, las cuales ejemplifican el dominio de los hombres sobre el espacio público, restringiendo la movilidad geográfica femenina. Por su parte Roxana Vásquez (2015) sostiene que "la ausencia de condiciones objetivas y subjetivas para garantizar el desarrollo de sus experiencias de libertad e igualdad tanto en la esfera pública como en la privada sigue siendo esquiva cuando no inexistente para la gran mayoría de mujeres." (Vásquez, 2015:13).

15 Entrevista aplicada en setiembre del 2019 en la ciudad de Chiclayo. Hombre de 22 años natural de Macaray. Llegó 11 días antes de la entrevista. Viajó con su pareja. 
Inclusive se ofrecerá dinero para tener favores sexuales o se les dirá que son portadoras del VIH. Todo tipo de historias en torno a su sexualidad será el marco perfecto para construir un estigma en torno a poblaciones cuya necesidad las impulsa a soportar este tipo de maltratos. El caso de una migrante menor de edad $^{16}$ refleja lo dicho debido a una mala experiencia:

Yo estaba en mi trabajo dándole información a un señor y una seńora separa al lado y dice: ay no, lo que quiere ella es sacarte tu dinero, es una prostituta barata, una veneca de mierda (expresa con mucha indignación). Yo le dije que no me falte el respeto porque yo estoy trabajando normal.

Escenas de robos y violencia ejercida por migrantes venezolanos que se suman a la alta tasa de criminalidad y acciones delictivas en el Perú tienden a encender posturas negativas de muchos peruanos y peruanas. Para entender tales opiniones, se pueden citar algunos casos polémicos. El más impactante fue el descuartizamiento de dos jóvenes peruanos propiciado por un grupo de venezolanos en San Martín de Porres que se convirtió en un video de circulación y consumo masivo por redes sociales en el año $2019^{17}$. Un segundo caso es el asesinato de un peruano ocurrido en un local de comida rápida en la ciudad de Lima, por un migrante venezolano en pleno horario de servicio y atención en enero del $2020{ }^{18}$. Otro caso de homicidio, ocurrido a fines de mayo del 2019, fue del recepcionista de un hostal a manos de una pareja venezolana que simularon ser clientes. ${ }^{19} \mathrm{Un}$ siguiente hecho fue del asalto de venezolanos con mano armada en una joyería durante el año 2018 que, según la PNP fue perpetrada por una la organización criminal "Los fuleros del Jockey" liderado por inmigrantes venezolano ${ }^{20}$.

16 Entrevista aplicada en la ciudad de Lima en julio del 2019. Mujer de 17 años con dos meses en Perú.

17 Recuperado de https://larepublica.pe/sociedad/2019/09/26/descuartizados-en-smp-nuevos-detalles-sobre-el-doble-asesinato-en-hostalsenor-de-sipan-atmp/

18 Recuperado de https://larepublica.pe/sociedad/2020/01/13/puntanegra-caen-118-venezolanos-en-bunker-donde-planeaban-crimenesministerio-del-interior-sicariato-homicidio-fotos/

19 Recuperado de https://elcomercio.pe/lima/policiales/callao-falsosclientes-matan-punaladas-recepcionista-hotel-robarle-200-soles-noticia-nndc-640319-noticia/

20 Recuperado de https://elcomercio.pe/lima/policiales/asalto-jockeyplaza-paso-dos-semanas-cronologia-noticia-533473-noticia/
Dichas situaciones delictivas fueron especialmente difundidas por medios de comunicación, sin el mayor análisis o comentario profesional, convirtiéndose en pretextos para generalizaciones cada vez mayores conllevando a recrudecer dichos estigmas. Un caso es el de una migrante en Cusco que protesta por las generalizaciones negativas que le cuestan a ella su tranquilidad: "Hay personas que tratan a uno bien y como hay venezolanos que han hecho cosas malas, nos titulan a todos por igual y no todos somos iguales" 21 .

El racismo y discriminación tendrían la forma de un espejo que constantemente atormenta el imaginario peruano que describe como injusta la preferencia de la mano de obra venezolana sobre la mano de obra peruana. Como sustento de ello, según el Instituto de Opinión Pública, el 50\% de peruanos está de acuerdo con que los inmigrantes venezolanos están despojando de empleos a sus compatriotas peruanos ${ }^{22}$, aunque en la Población económicamente activa participa apenas el 2\% de los 862 mil migrantes que se encontraban en el Perú al año 2019. ${ }^{23}$ Cabe destacar que en el contexto global, y dada las desigualdades entre regiones mundiales, los migrantes se presentarán ante la opinión pública de las sociedades receptoras "como culpables de muchos de los males que las aquejan: desmantelamiento del Estado de bienestar, achicamientos de las clases medias, desempleo y precarización laboral, etc.” (Delgado, 2016: 170). De esta manera, cada vez más los Estados vincularán las migraciones a su propia seguridad nacional situándolas entre sus principales preocupaciones "en un rango de gravedad que las equipara al terrorismo y la criminalidad transfronterizos" (Dos Santos, 2012: 434).

La población peruana comenta que es injusto el emplear o brindar auxilio a los migrantes venezolanos frente a la urgente acción en favor de los peruanos en situación de similar pobreza. También se increpa la incapacidad del Estado por impedir la llegada de más migrantes desde Venezuela y no promover la sa-

21 Entrevista realizada en Cusco con una mujer con una nińa en los brazos vendiendo caramelos. La mujer tenía aproximadamente 30 años de edad.

22 Boletín del IOP $\mathrm{N}^{\circ} 157$ Estado de la Opinión Pública Creencias y actitudes hacia los inmigrantes venezolanos en el Perú de febrero del 2019. Recuperado de http://repositorio. pucp.edu.pe/index/bitstream/handle/123456789/134548/ 23 Ídem 
lida de los que poco a poco están instalándose en el Perú. Otro testimonio recogido comparte su propia experiencia: "Insultan mucho, dicen flojo, que anda a trabajar. Hay gente que trata bien y mal" ${ }^{24}$. Cabe destacar que es en las ciudades de la costa, en especial en Lima a decir de los migrantes venezolanos entrevistados, se vislumbra una xenofobia más recrudecida: “iAllá no puedes estar así vendiendo porque la gente pasa y te menta la madre de a uno" 25 señala un entrevistado en Cusco, dando cuenta de las diferencias de discriminaciones sufridas de acuerdo a la ciudad. Este tipo de discurso se retroalimentara de cierto temor a la pérdida de oportunidades laborales y reconocimiento urbano de los propios nacionales, provocando el rechazo hacia la población migrante tomando supuesta distancia del racismo, en tanto "se considera que es legítimo defenderse frente la amenaza que representan estas personas y porque, en una época de crisis, hay que dar prioridad a los nuestros" (Aguilar-Idañez, 2017: 111).

Para profundizar dicho fenómeno se pueden citar investigaciones en el continente europeo, en donde se vislumbra una creciente inmovilidad e indiferencia de la sociedad y de las instituciones, pese a la crisis de humanidad vivida por la población refugiada, lo cual reflejaría una profunda paradoja: "vivimos en sociedades que consideran los derechos humanos y los valores democráticos como el núcleo central de nuestra identidad, pero nos mostramos apáticos e indiferentes o, incluso beligerantes, hacia personas que buscan refugio". (Aguilar-Idañez, 2017: 106). De esta manera, el debate en torno a la migración ha generado la necesaria "superposición de diversas formas de destierro, coacción y despojo en una misma experiencia vital desbordando con ello la capacidad descriptiva y explicativa de la migración, en su acepción clásica (Osorio, 2014: 23). Resuenan los comentarios de Rocha (2017) al respecto, en tanto "los Estadosnación no pueden interpretar o dar respuestas a los diversos tipos de demandas sociales, siendo necesario reinventar el concepto de ciudadanía desde la heterogeneidad cultural” (Rocha, 2017: 37).

24 Entrevista aplicada en Cusco en octubre del 2019. Hombre de 24 años. Llegó a Perú de la ciudad de Margarita en octubre del 2018. Es casado y tiene un nińo de 4 ańos. Toda la familia vive en Perú. Trabaja vendiendo chutepes en Cusco

25 Ídem.

\section{Los inmigrantes venezolanos frente a la xenofobia en el Perú}

En Lima, como respuesta a la gran cantidad de noticias negativas sobre la migración venezolana ofrecida por los medios de comunicación de manera masiva, se podía apreciar carteles en puentes peatonales anuncios como "los buenos somos más", entre otros, para convencer a la población de un mínimo apoyo a su trabajo de barrer puentes. Como parte de este proceso, para abril del 2018 se conoció de múltiples casos de migrantes venezolanos sosteniendo pancartas en las que pedían perdón por los delitos cometidos a manos de ciudadanos venezolanos. ${ }^{26}$ Asimismo, se apreciaban vendedores ambulantes en la ciudad de Lima subiendo a líneas de transporte pidiendo disculpas a los pasajeros en nombre de todo venezolano que haya cometido crímenes, asegurando no ser nocivos para la sociedad peruana. A continuación se presenta el discurso de un ambulante en un ómnibus en donde, si bien no negaba los crímenes cometidos por otros venezolanos, insistía en la valoración de otros que merecerían algún tipo de apoyo. Inclusive compartiría parte de sus destrezas con la esperanza de conseguir algún trabajo:

Pero estoy buscando alquiler y sigo buscando la forma de como poder darle una estabilidad a mi familia, de pronto usted ya desconfía, de pronto usted dirá que mucho venezolanos son rateros, mentirosos, ladrones, asesinos, tanta cosa, alzados, altaneros, pero hay venezolano educado papa con valores, modales, con buenas intenciones, activos, trabajadores, que bueno están buscando la manera de llevar el pan cada día al hogar. Mira yo sé de carpintería, yo se trabajara la herrería, la fundidora. Mi esposa ella es administradora tributaria y al igual que yo también se vino a ganar la vida honradamente papa si, si le pregunto usted alquila habitación papi, ustedes creen que me puedan alquilar una habitación, hablo de corazón papa, porque la verdad ahora nosotros estamos en la calle, no tenemos en estos momentos donde estar. ${ }^{27}$ 
En un testimonio recolectado en Ayacucho ${ }^{28}$, un migrante venezolano relataba que su salida de Lima se debió a la inclemente ola de insultos que recaía sobre él. Según sostenía había perdido el trabajo debido a ello:

Entrevistado: Por la situación, mano, muchos compatriotas que están haciendo lo malo y la gente nos está viendo de otra manera.

Entrevistador: ¿Y qué te ha dicho la gente?

Entrevistado: No, de todo papá, mira: "Que me vaya a mi país" "que no sé qué", coño, lamentablemente por uno se paga por todos, que vamos hacer (...) La mayoría en Lima está así, está huyendo de Lima, por eso mismo, porque hay mucha xenofobia.

Su testimonio era claro: estaba huyendo de Lima para encontrar algún otro espacio en el que pueda trabajar. ¿Acaso habría alguna motivación para que las personas hayan cambiado su actitud hacia él? Según sostenía, todo iba bien hasta que las noticias empezaron a generar denuncias hacia todo venezolano posible: "(Iba bien) Chévere, trabajando, claro trabajando, porque uno estaba pendiente de trabajar, como uno no se mete con nadie pero ahora igualmente, uno no se está metiendo con nadie, se la están agarrando con uno". Su testimonio no era el único.

Una familia venezolana ${ }^{29}$ que tenía pocas horas de haber llegado a Ayacucho, de la mano con una pequeña bolsa de caramelos, sostenía que se encontraba alejándose de Lima y de cualquier sitio en donde se sientan denigrados: "Lo que pasa es que teníamos información por nuestros amigos que se han establecido en Ica... estábamos buscando un sitio que no haya venezolanos (...) Estábamos buscando algo tranquilo, que la gente no nos venga con desprecio y toda esa cosa”. En efecto, una de las cosas que más inquietaba a dicha familia era la insistencia de algunos peruanos en recriminarles que regresen a su país a trabajar allá, según relata la pareja de esposos:

28 Hombre de 30 años, natural de Guárico, Venezuela. Lleva dos ańos en Perú y recientemente llegado a Ayacucho. Se encontraba pidiendo limosna en la calle. Entrevista de octubre del 2019.

29 Entrevista a un hombre de 36 y una mujer de 30 ańos, ambos casados. Junto a ellos dos de sus menores hijos una de semanas de nacida y, la otra, de 6 ańos de edad. Son naturales de Caracas. Aunque llevaban un año y medio en Lima, habían llegado aquel mismo día a Ayacucho.
Mujer entrevistada: Por lo menos la situación que está pasando ahorita que mucha gente pregunta porque nos venimos, porque venimos con los niños, y en realidad eso causa un poco de molestia. Hombre entrevistado: Sí, bueno, eso es como que un defecto del peruano en sentido de que porque se vinieron, uno está pasando necesidades.

Mujer entrevistada: Porque no luchamos allá, como si fuera tan fácil, es una situación bien complicada. Hombre entrevistado: El sueldo mínimo son cuarenta mil bolívares, con cuarenta mil bolívares compramos un kilo de arroz. Es como si tú ganaras semanalmente aquí un sol, que haces aquí con un sol.

Dichos resultados se acompañan de estadísticas publicadas por el Instituto Nacional de Estadística e Informática- INEI, el cual sostiene que un 35,6\% de inmigrantes venezolanos han experimentado un trato discriminatorio en distintos espacios, e inclusive un $26,8 \%$ de ha sufrido algún tipo de maltrato verbal por parte de agentes de entidades públicas o de sus empleadores. ${ }^{30}$ Siguiendo esta línea, las investigaciones de Cuevas (2018) arrojan resultados en donde "los barrios se convierten en incubadoras de intolerancia y xenofobia, paradójicamente inculpando a los venezolanos por los malestares de una ciudad cambiante" (Cuevas, 2018: 88).

En líneas generales se desarrollará una valoración macro negativa hacia la migración venezolana aunque, en aparente contradicción, se sostendrá una amable relación micro con los venezolanos que conocerá día a día, intercambiando pareceres, experiencias y opiniones. Un ejemplo de ello es un venezolano en Puerto Etén, Chiclayo, quien gozó de trabajo desde su llegada, sintiéndose privilegiado al respecto: "la mejor experiencia que he tenido hasta el momento es el trato que he recibido de los peruanos y la oportunidad de empleo que me han ofrecido en Chiclayo" ${ }^{31}$. Inclusive la familia venezolana que había llegado a Ayacucho sostenía que "de verdad no podemos negar que mucha gente nos ha ayudado muchísimo pero existe esa otra parte, una minoría”.

30 INEI. Condiciones de vida de la población venezolana que reside en Perú. Resultados de la "encuesta dirigida a la población venezolana que reside en el país. 2019.

31 Entrevista aplicada en Puerto Eten, Chiclayo en setiembre de 2019. Hombre de 23 ańos de Mérida. Vive con toda su familia en Perú. Trabaja como mesero en un restaurante de Puerto Etén. 
Cabe destacar aquí una diferencia entre dichos ámbitos. Un aspecto general que no distingue a venezolanos y provoca la estructuración de estigmas en busca de una mirada muy negativa hacia todo ciudadano venezolano. De allí los insultos y enfrentamientos cotidianos que se dan en las calles y espacios privados protagonizada por actores anónimos entre sí. Otro ámbito particular en donde venezolanos y peruanos interactúan naturalmente diferenciando a cierto venezolano o venezolana como miembro distinto a la generalidad criticada. Esto debido a las relativas diferencias interactivas que se pueden llegar a tener cuando la recurrencia es constante entre ambas personas. De allí la frase "no todos los venezolanos son asî" o "yo tengo un amigo venezolano que no es asî". Ejemplo de ello es la ayuda de algunos peruanos que han apoyado a los más inmigrantes con mayor necesidad ${ }^{32}$. La suma de dichos micro relaciones intersubjetivas nos permite describir la importante inserción de la población venezolana en el mundo económico social y cultural del país y la obvia búsqueda de satanizar a una población que, a pesar de su interacción cotidiana con la población peruana, no deja de construir, a su vez, una serie de rencores hacia la actitud peruana contra ellos y ellas. Lo cierto es que el Perú atraviesa una situación de difícil control al tener que enfrentar amplios puntos de vista xenofóbicos frente a una política de Estado de buena vecindad para con los migrantes, en tanto sigue multiplicándose en los migrantes venezolanos la "superposición de diversas formas de destierro, coacción y despojo en una misma experiencia vital" (Osorio, 2014: 23).

\section{Conclusiones}

La migración venezolana en el Perú viene generando una serie de dificultades de inserción laboral y cultural debido a la creciente ola de prejuicios y estigmatizaciones por parte de la población peruana hacia la población migrante. De acuerdo a la data analizada se encuentra una relación estrecha entre espacios urbanos masivos y discriminación, siendo la ciudad de Lima la que peor tratará al migrante venezolano. Los

32 Recuperado de https://elcomercio.pe/lima/personajes/coronavirusen-peru-mujer-que-alimento-mendigos-del-centro-de-lima-durantecuarentena-recibe-ayuda-para-seguir-con-su-noble-iniciativa-coronavirus-noticial testimonios refieren no solo insultos en general, sino un maltrato especialmente denigrante hacia la mujer venezolana, circunstancias de explotación laboral y de engaño en contrataciones ilegales. Todo ello suma una serie de amenazas que obligan a los migrantes no solo a migrar a Lima, sino a volver a migrar a otras ciudades escapando del abuso y del maltrato psicológico que sufren cada vez más.

De acuerdo a lo establecido en el espectro bibliográfico existe una relación entre la dinámica xenofóbica generalizada en el mundo y el caso peruano, sin embargo en el Perú aun vienen construyéndose incipientes fórmulas estigmatizadoras que deben enfrentar redes familiares y amicales venezolanas que han sabido responder a tales dificultades a partir del fortalecimiento de sus propias redes, aunque el costo es demasiado alto: diferenciase y atomizarse en torno a redes venezolanas que crearían distancias cada vez mayores a los peruanos. Ello no debería sorprender en un estudio migratorio de este tipo en tanto la población está convencida de su regreso al país de origen. Ello explica los pocos casos de construcciones familiares de dos nacionalidades. El patriarcalismo imperante no solo dificulta, sino que espanta todo tipo de cercanía con la mujer venezolana que ve con ojos de desconfianza tanto a mujeres como hombres peruanos.

El caso de los hombres es distinto, en la medida que deben aprender a convivir con una suerte de credos conservadores que conllevan a un comportamiento muy acomedido para con las mujeres peruanas evitando todo tipo de provocación de género que podría generarles una dura reprimenda por parte de las autoridades o del público transeúnte. La migración ofrece personas de distinta índole, tanto familias migrantes, familias transnacionales migrantes con miembros aquí y allá, personas solteras que viven para sostener a sus familias de padres y hermanos en Venezuela. Se comprueba el comportamiento muy diferenciado entre unos y otros, evidenciándose el compromiso del trabajo como un asidero que disminuiría el estrés causado por los diversos problemas vividos en Perú. Si las familias trabajan duro por sus miembros, las familias trasnacionales, los solteros y solteras lo hacen para ayudar o incrementar el capital en sus países de origen. Ven la crisis económica no solo como una desgracia, sino como una oportunidad para generar un bienestar futuro lo suficiente- 
mente óptimo en beneficio de sus familias y de ellos mismos.

La clandestinidad que opera en las explotaciones laborales, en el comercio ambulatorio y en la prostitución debe atravesar una serie de dificultades. La incertidumbre que conlleva a degenerar el único asidero verdadero que poseen en un país de trato belicoso como el Perú: la acumulación de capital que augura un mejor futuro. Se les engaña, no se les colabora lo suficiente acaso provocando una preocupación muy profunda llevándoles a mendigar en muchos casos o en otros a inventar trabajos como los de limpiar puentes peatonales. A ello se le suma situaciones de peligro constante como el de la prostitución que, en los casos estudiados, pertenecían a mujeres cuyas madres e hijos se encontraban en Venezuela, siendo la razón de sus urgencias económicas. Frente a situaciones de emergencia vital, la moral que se resignificaría en un contexto completamente nuevo un ámbito sin mayores redes de reconocimiento social.

\section{Recomendaciones}

Debido a las vivencias compartidas, a los testimonios catárticos oídos, y a la sistematización de ocurrencias que hicieron noticia en la realidad social peruana, se puede plantear la urgencia y necesidad de reflexionar sobre lo que representa la migración venezolana en el Perú. Por ello recurrimos a este apartado para generar algunas reflexiones finales.

La noción de extranjero o de ajeno a un país no solo es artificial, sino, en el caso peruano, es paradójica considerando la enorme distancia cultural entre unos y otros. Ello se reproduce en condiciones de asimetría que, desde antes de la migración, ya existía y era condenable. El desconocimiento de las culturas otras, de la pobreza extrema, de los atropellos políticos con numerosas comunidades o de la contaminación medioambiental en contra de múltiples etnias nos permiten saber que la inclemente separación entre la urbe y el resto del país es una realidad continua y repetida. La migración re crea un grupo de personas a quienes se bautizan como el otro, el enemigo, el peligro, la perdición. Mientras que en otros países se apela a una amenaza al nacio- nalismo uniforme, en nuestro país la migración debería representar un elemento más que sume la gran heterogeneidad que nos catapulta como un país de enorme riqueza cultural.

Es importante entender que el mundo está cambiando y el Perú cambia con él, por lo cual se va convirtiendo en un país con muchas posibilidades de transformarse en epicentro de migraciones a nivel de los países más pobre de la región sudamericana e, incluso, mundial. Todo país en vías de desarrollo, y que vaya disminuyendo su población joven, como es el caso peruano, vive poco a poco un incremento de las migraciones en su propio país, salvaguardando la mano de obra joven que sería urgente para las poblaciones en edad de jubilación. Aprender desde ya lo que podría significar solo el inicio no solo es algo importante para nuestro futuro demográfico, sino para avizorar una perspectiva positiva frente al mundo de lo que podemos hacer como país ofertante de trabajo, de cultura y de solidaridad.

La migración venezolana en el Perú representa una gran oportunidad para reconocer nuestro etnocetrismo al ser incapaces de detenernos a pensar en otras realidades nacionales en donde el hambre y la desesperación pululan en el día a día; una oportunidad para reconocer nuestro racismo que distingue a las personas por los colores de piel, las actitudes para interactuar, el modo de hablar, al fin, en cualquier pretexto para excluir a personas que identificamos como diferentes y como ajenos a nuestro propio territorio en una suerte de endogámica forma de crecer como país; una oportunidad de reconocernos como patriarcales y racistas al ofender, degradar y violentar a personas venezolanas en las calles, en el trabajo y en el imaginario constantemente, como si se tratase de una consigna por salvaguardar al país del pecado migrante venezolano. Finalmente, es una oportunidad para reconocer la pésima condición de los medios de comunicación que no cumplen un rol pedagógico, de discusión, de aprendizaje y de crítica en torno a temas de sumo interés nacional: pornografía de la violencia y prejuicios generalizados se transmiten confundiendo aún más a la población en lo que debería significar un momento de gran trascendencia en nuestra historia nacional, el ingreso al cosmopolitismo mundial. 


\section{Bibliografía}

Aguilar-IdáńEz, María José, \& Buraschi, Daniel (2017). "Migrantes y refugiados: apuntes clave para un nuevo relato". Revista Lusófona de Educação, (37), 103-116.

Albarrán, María de Lourdes, \& Manero Brito, Roberto (2010). “La migración: una institución”. Enseñanza e Investigación en Psicología, 15 (1), 159-181.

Albó, Xavier (2008). Movimiento y poder indígena en Bolivia, Ecuador y Perú. La Paz: PNUD, CIPCA.

Bobes, V. (2017). "ONG de migración como actores de un campo de acción solidaria”. En Migración y desarrollo, 15(28). Pp. 115-146.

Buller AM., Vaca V., Stoklosa H., Borland R. y Zimmerman, C. (2015). Explotación Laboral, Trata y Salud de los Migrantes: Hallazgos en Diversos Países sobre los Riesgos y Consecuencias para la Salud de los Trabajadores Migrantes y las Víctimas de Trata. Organización Internacional para las Migraciones y London School of Hygiene \& Tropical Medicine. Organización Internacional para las Migraciones OIM. Disponible en https://publications.iom.int/system/files/pdf/explotacion_laboral_trata_y_salud_de_ los_migrantes_0.pdf

Maldonado, Carlos (2018). Protección social y migración. Una mirada desde las vulnerabilidades a lo largo del ciclo de la migración y de la vida de las personas. Santiago: CEPAL.

Castel, Robert (2010). El ascenso de las incertidumbres. Trabajo, protecciones, estatuto del individuo. Buenos Aires: Fondo de Cultura Económica.

Castro Franco, Alexandra (2010). Pobreza y migraciones. Revista Derecho del Estado, (24), 65-80.

Coraza, Enrique (2014). "Territorialidades de la migración forzada. Los espacios nacionales y transnacionales como estrategia política." Espacialidades. Revista de temas contemporáneos sobre lugares, politica y cultura, 4 (1), 199-221.

Cuevas-Calderón, Elder (2018). "Reconfiguración social: entre la migración y la percepción inseguridad en Lima, Perú". URVIO, Revista Latinoamericana de Estudios de Seguridad, núm. 23, 2018, Julio-Diciembre, pp. 73-90

Dos Santos, Alfredo (2012). Migraciones forzosas y las nuevas "categorias" de desplazados internos-desplazados medioambientales y del desarrollo: problemas y desafios para el sistema internacional de protección El modelo de respuesta regional de la Unión Africana desde la soberania como "responsabilidad de proteger" y su posible pertinen- cia global. (Tesis doctoral) Universidad Complutense de Madrid, Madrid, Espańa.

Delgado, Raúl (2016). "Notas sobre la cuestión laboral y migratoria hoy: migración forzada, desarrollo desigual e imperialismo". En Theomai, (33), 157-173.

DunNing, Eric y Norbert, Elias 1992. Deporte y ocio en el proceso de la civilización. Madrid: Fondo de Cultura Económica.

Escárzaga, Fabiola, \& Abanto Llaque, Julio, \& Chamorro G., Anderson (2002). "Migración, guerra interna e identidad andina en Perú". Política $y$ Cultura, (18), 278-298.

EtXebarria, Xabier (2003). La ciudadanía de la interculturalidad. En Ciudadanias inconclusas. El ejercicio de los derechos en sociedades asimétricas. N. Vigil y R. Zariquiey (Eds.) Lima; GTZ y PUCP. Pp. 91-110.

García, José y Armas, Enrique (2011). "Transnacionalidad y migración” En CIMEXUS Vol. 6, №2. 99-118.

García, Manuel y Restrepo, Jair (2019). Aproximación al proceso migratorio venezolano en el siglo XXI. En Hallazgos no 32. Pp. 63-82.

Guerra, María José (2017). "Inseguridad humana, migración y supervivencia. Género y derechos humanos. En Astrolabio. Revista internacional de filosofía año. 2017, núm. 19. ISSN 1699-7549. pp. 190-206.

Guerra, María José (2012). "Migraciones, género y ciudadanía”. Astrolabio: Revista internacional de filosofía. Núm.13, pp.201-210.

KyмLicka, Will (2003). Estados multiculturales y ciudadanos interculturales. En R. Zariquiey, Ed., Realidad multilingüe y desafio intercultural. Lima: GTZ, Ministerio de Educación y PUCP. Pp. 47-81.

Oficina General de Planeamiento y Presupuesto (2018). Caracteristicas Sociodemográficas de ciudadanos venezolanos que tramitaron su Permiso Temporal de Permanencia-PTP en el Perú 2017-2018. Recuperado de: https://www.migraciones.gob.pe/comunicaciones/ publicaciones/Caracteristicas-sociodemograficas-deciudadanos-venezolanos.pdf

Osorio, Flor (2014). "Más allá de las migraciones internas. Destierro y despojo en la guerra”. Iztapalapa, Revista de Ciencias Sociales y Humanidades, (76), 19-51.

Ovando, Gabriela (2008). A grandes males, grandes reformadores. Ensayos sobre la recuperación de la identidad indígena. La Paz: Plural Peláez Paz, Carlos. (2016) "De la emergencia a la inclusión social y laboral: derechos humanos y personas refugiadas". En Revista de Educación Social. Año. 2016, núm. 23. pp.220-242 
Retamozo, Tatiana (2014). "Las migraciones en un mundo globalizado. Migración y género”. En Crítica, núm. 994, noviembre-diciembre, 2014, pp. 57-61

Rocha Pérez, Rodrigo (2017). Ciudadanía cultural y migración desde la perspectiva de género. Contextos: Estudios De Humanidades Y Ciencias Sociales, (35), 21-40.

Sen, Amartya (2000). El desarrollo como libertad. Barcelona: Editorial Planeta.

Vallejo, Elizabeth y Rivarola, Ana (2013). "La violencia invisible: acoso sexual callejero en Lima Metropolitana y Callao" En Cuadernos de Investigación IOP $n^{\circ} 4$.
Disponible en: http://repositorio.pucp.edu.pe/index/ handle/123456789/34946

VArese, Stefano (2011). Los pueblos indígenas combatiendo el nacionalismo de Estado y el globalismo corporativo. En Louis Meyer y Benjamín Maldonado (Coords). Comunidalidad, educación y resistencia indígena en la era global. Oaxaca:CSEIIO. Pp. 291-306.

VÁsquez, Roxana (2015). La violencia contra las mujeres en el Perú. Lima: Cooperación Alemana. Disponible en: https://www.mujereslibresdeviolencia.usmp.edu. pe/wp-content/uploads/2015/09/giz2015-es-estudiocambios-actitudes-VF.pdf. 